\title{
Processing-structure-property relations of chemically bonded phosphate ceramic composites
}

\author{
H A COLORADO ${ }^{1,2,6, *}$, C HIEL ${ }^{3}$ and H T HAHN ${ }^{1,4,5}$ \\ ${ }^{1}$ Materials Science and Engineering Department, University of California, Los Angeles, CA 90095, USA \\ ${ }^{2}$ Universidad de Antioquia, Mechanical Engineering. Medellin-Colombia \\ ${ }^{3}$ Composite Support and Solutions Inc. San Pedro, California \\ ${ }^{4}$ Mechanical and Aerospace Engineering Department, University of California, Los Angeles, CA 90095, USA \\ ${ }^{5}$ California NanoSystems Institute, University of California, Los Angeles, CA 90095, USA \\ ${ }^{6}$ Present address: MAE 38-137B, Engineering IV, 420 Westwood plaza, Los Angeles, CA 90095, USA
}

MS received 4 October 2009; revised 17 November 2009

\begin{abstract}
Mechanical properties and microstructures of a chemically bonded phosphate ceramic (CBPC) and its composite with $1.0 \mathrm{wt} \%$ graphite nanoplatelets (GNPs) reinforcement have been investigated. Microstructure was identified by using optical and scanning electron microscopes, $X$-ray tomography, and X-ray diffraction. In addition, weight loss of the resin at room temperature was studied. The microstructure characterization shows that CBPC is itself a composite with several crystalline (wollastonite and brushite) and amorphous phases. SEM and micro tomography show a homogeneous distribution of crystalline phases. Bending and compression strength of the CBPC was improved by reducing bubbles via preparation in vacuum.
\end{abstract}

Keywords. Chemical bonded ceramics; ceramic-matrix composites; particle-reinforced composites; mechanical properties.

\section{Introduction}

High temperature manufacturing processes contribute to global warming and this is especially significant in the processing of cementitious and ceramic materials. It is well established that between 900 and $1100 \mathrm{~kg}$ of $\mathrm{CO}_{2}$ is emitted for every $1000 \mathrm{~kg}$ of Portland cement produced in the US. This quantity depends on the fuel type, raw ingredients used and the energy efficiency of the cement plant (Environmental Protection Agency 2005; NRMCA 2008).

However, the emerging class of chemically bonded phosphate ceramic (CBPC) materials do not require a high temperature process (Arun 2004). In addition, they possess excellent fire resistance and thermal insulation; manufacturing is also inexpensive and environmentally harmless. Some researchers name these materials as CBPC (Arun 2004) and others (Mosselmans et al 2007) prefer phosphate cements (PC), or inorganic phosphate cement (Alshaaer 2006). In the present work, we use CBPC which is the result of mixing calcium silicate (wollastonite, $\left.\mathrm{CaSiO}_{3}\right)$ and phosphoric acid $\left(\mathrm{H}_{3} \mathrm{PO}_{4}\right)$, to produce calcium phosphates (brushite, $\mathrm{CaHPO}_{4} \cdot 2 \mathrm{H}_{2} \mathrm{O}$, $\mathrm{CaHPO}_{4}$ ). For molar ratios (phosphoric acid/wollastonite) between 1 and 1.66 (Mosselmans et al 2007), three

*Author for correspondence (hcoloradolopera@ucla.edu) different calcium phosphates (brushite, monetite and calcium dihydrogenphosphate monohydrate) are possible. The reactions producing monetite $\left(\mathrm{CaHPO}_{4}\right)$ and calcium dihydrogenphosphate monohydrate $\left(\mathrm{Ca}\left(\mathrm{H}_{2} \mathrm{PO}_{4}\right)_{2} \cdot \mathrm{H}_{2} \mathrm{O}\right)$ are presented in (1) and (2) respectively (Mosselmans et al 2007).

$$
\begin{gathered}
\mathrm{CaSiO}_{3}+\mathrm{H}_{3} \mathrm{PO} 4=\mathrm{SiO}_{2} \cdot y \mathrm{H}_{2} \mathrm{O}+\mathrm{CaHPO}_{4} \\
+(1-y) \mathrm{H}_{2} \mathrm{O} \\
\mathrm{CaSiO}_{3}+2 \mathrm{H}_{3} \mathrm{PO}_{4}+z \mathrm{H}_{2} \mathrm{O}= \\
\mathrm{SiO}_{2} \cdot z \mathrm{H}_{2} \mathrm{O}+\mathrm{Ca}\left(\mathrm{H}_{2} \mathrm{PO} 4\right)_{2} \cdot \mathrm{H}_{2} \mathrm{O}
\end{gathered}
$$

Since the reaction is extremely fast and exothermic, dilute acid is required to make samples. This affects the strength because the air bubbles produced are difficult to remove, sometimes resulting in a highly porous material. We developed a procedure, to increase the curing time and pot life, reduce viscosity, and avoid a porous material.

The materials phases resulting from (1) and (2) above are well-known in biomaterial applications. For instance, brushite has a higher solubility than hydroxyapatite under physiological conditions, so it is commonly used as an implant. It is sparingly soluble at physiological $\mathrm{pH}$ $\left(2 \operatorname{logKsp}=56.63\right.$ at $\left.37^{\circ} \mathrm{C}\right)$. Despite this, brushite cements are typically weaker than the majority of apatite cements (Grover et al 2005). 
There is a great of deal of research on processing organic cements at low temperatures. In fact, calcium orthophosphate bioceramics (e.g. hydroxyapatite) have been investigated as implant materials since the early twentieth century (Albee and Morrison 1920). Calcium phosphate based materials, proposed two decades ago by LeGeros et al (1982) and Brown and Chow (1976) as synthetic bone substitutes, are widely used in reconstructive surgery (Nihouannen et al 2008; Tamimi et al 2008). However, shear strength of brushite as a bone filling material and hydroxyapatite as a structural biomaterial is still fairly low: it has been reported as only $2.9 \mathrm{MPa}$ and $9.8 \mathrm{MPa}$, respectively (Charrière et al 2001). Brushitebased biomaterials are also of special interest in bone regeneration due to their biocompatibility and biodegradability, but the compressive strength of brushite calcium phosphate cements has been reported as only $9 \mathrm{MPa}$ (Grover et al 2008).

Another body of research, however, has examined the processing of organic cements at high temperatures. It is found that some high resistance calcium phosphates, when acting as bioactive bone cements made from wollastonite and apatite powders, have much better mechanical properties. For instance wollastonite containing glass ceramic with a bending strength of $124 \mathrm{MPa}, 72 \mathrm{MPa}$ for hydroxyapatite cement and $69 \mathrm{MPa}$ for $\beta$-tricalcium phosphate cement. However, all of these were sintered in high temperature processes, some higher than $1000^{\circ} \mathrm{C}$ (Masahiko et al 1998).

Reported bending strength for CBPC without thermal treatment is $8 \mathrm{MPa}$ and after heating to $1000^{\circ} \mathrm{C}$ is $11 \mathrm{MPa}$. Ageing at ambient conditions for 12 months and 20 months increased strengths to $12 \mathrm{MPa}$ and $16 \mathrm{MPa}$, respectively (Alshaaer 2006).

In this paper we show an improved CBPC eliminating macro and micro bubbles and using graphite nanoplatelets (GNPs), with more than twice the strength previously reported for general structural applications of CBPC (Alshaaer 2006), without involvement of thermal treatment or ageing. Obviously, there is huge decrease in costs by obtaining these mechanical properties without ageing and thermal processing.

In addition, we present an alternative solution for possible biomedical implants using CBPC processed at room temperature.

These improvements also qualify CBPC materials for demanding structural applications in many industries, including aerospace. Further, this solution is economical and environment friendly because it was achieved without ageing or thermal treatment.

\section{Experimental}

A simplified flow chart of the process is presented in figure 1 .

\subsection{Sample preparation}

A patented phosphoric acid formulation from Composites Solutions and natural wollastonite powder (M100 from Minera Nyco S.A.) were mixed mechanically to obtain a 1.2 ratio liquid/powder. At this ratio a chemically neutral product results. The chemical composition is presented in table 1 .

GNPs, product number 827 from Asbury Graphite Mills Inc, were added to the CBPC mixture, with a mean surface area of $113 \mathrm{~m}^{2} / \mathrm{g}$ and a minimum of $99 \mathrm{wt} \%$ of carbon.

During the mixing of the wollastonite powder and phosphoric acid, air bubbles appeared, decreasing the mechanical properties. These bubbles were mainly micro size. In order to solve this problem, different mixing conditions were tried. Vacuum processing and cooling of the materials improved the manufacturing by decreasing the bubbles and viscosity of the mixture correspondingly.

\subsection{Manufacturing parameters}

2.2a Temperature: The pot life of mixed CBPC resin is dependent on the temperature of both the phosphoric acid and wollastonite powder as shown in table 2 .

A related significant observation is the decreased viscosity of the cooled liquid. As such the cooled acid allows the fabrication of void-free material since there is enough time to remove air bubbles. In addition, manufacturing of samples or parts is easy since impregnation of molds is high.

$2.2 \mathrm{~b}$ Vacuum processing: Vacuum assisted manufacturing at $0.01 \mathrm{MPa}$ for $1 \mathrm{~h}$ was performed in a vacuum system (Fisher Scientific Iso Temp Vacuum Oven Model $280 \mathrm{~A}$ ) at room temperature. This vacuum process reduced air bubbles, improved mechanical properties of CBPC, and also decreased material weight loss and shrinkage.

2.2c Mixing methods: Different procedures were tested: mechanical mixing, planetary centrifugal mixing $\left(\right.$ Thinky $\left.^{\circledR}\right)$, shear mixing and ultrasonic horn mixing.

For the CBPC resin mechanical mixing was the most practical and economical to achieve. The mixing was done for $5 \mathrm{~min}$, followed by $40 \mathrm{~min}$ of exposure to vacuum.

For the CBPC/GNPs, 1 wt.\% of GNPs 4827 was added: mechanical mixing using metallic blades resulted in poor mechanical properties. Therefore, GNPs were first mixed separately in the acid, and shear mixing (magnetic stirrer), sonicator, and Thinky mixing were attempted. Based on achieved mechanical properties, shear mixing was selected over the more expensive Thinky and ultrasonic horn assisted mixing. 


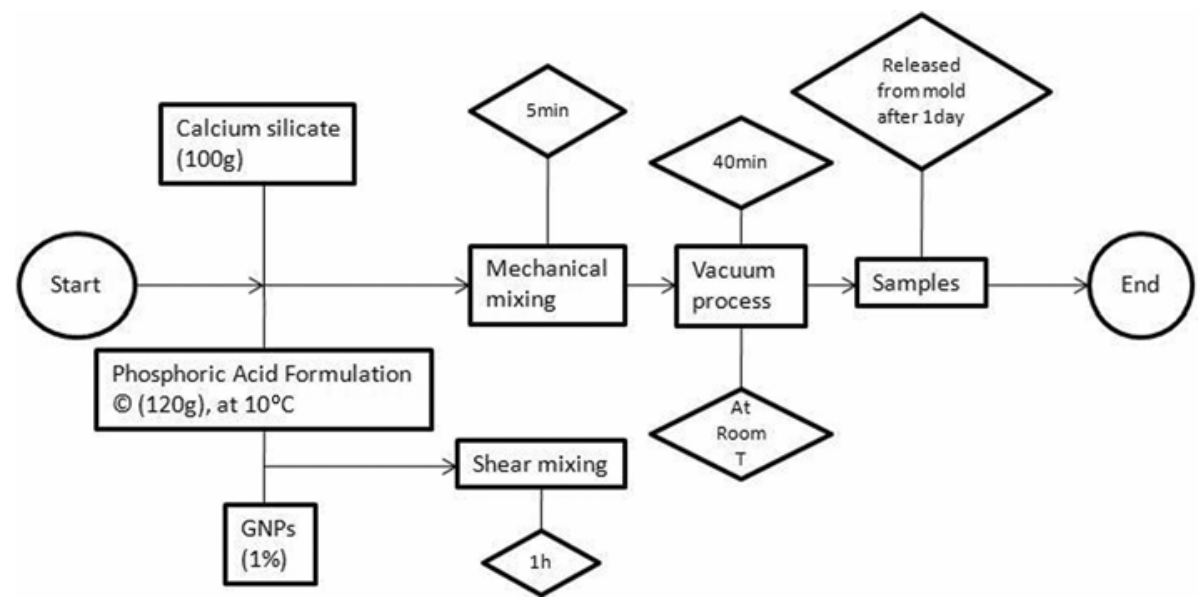

Figure 1. Simplified flow chart of the process.

Table 1. Chemical composition of wollastonite powder $100 \mathrm{in} \mathrm{wt} \%$.

\begin{tabular}{cccccccc}
\hline $\mathrm{CaO}$ & $\mathrm{SiO}_{2}$ & $\mathrm{Fe}_{2} \mathrm{O}_{3}$ & $\mathrm{Al}_{2} \mathrm{O}_{3}$ & $\mathrm{MnO}$ & $\mathrm{MgO}$ & $\mathrm{TiO}_{2}$ & $\mathrm{~K}_{2} \mathrm{O}$ \\
\hline 46.25 & 52.00 & 0.25 & 0.40 & 0.025 & 0.50 & 0.025 & 0.15 \\
\hline
\end{tabular}

Table 2. Effect of temperature of raw materials on the pot life.

\begin{tabular}{lcc}
\hline $\begin{array}{l}\text { Phosphoric acid } \\
\text { temperature }\left({ }^{\circ} \mathrm{C}\right)\end{array}$ & $\begin{array}{c}\text { Wollastonite powder } \\
\text { temperature }\left({ }^{\circ} \mathrm{C}\right)\end{array}$ & $\begin{array}{c}\text { Pot life } \\
(\mathrm{min})\end{array}$ \\
\hline RT $\left(23^{\circ} \mathrm{C}\right)$ & 23 & 30 \\
10 & 23 & 40 \\
10 & 10 & 60 \\
3 & 3 & 90 \\
\hline
\end{tabular}

2.2d Material molds: Stainless steel, aluminum, silicone rubber and Teflon ${ }^{\circledR}$ fluoropolymer were used. The best results were obtained using Teflon ${ }^{\circledR}$ because it is easy to release and provides good dimensional control. Aluminum mold is not a good option as it reacts chemically with the phosphoric acid-based liquid. When the material becomes solid, the CBPC samples are difficult to release, even using an inorganic mold release. Stainless steel has a similar but weaker reaction with the CBPC. Based on these observations of the adhesion of CBPC to metal molds, additional research is being conducted to optimize the adhesion in metal-CBPC laminar composites. Finally, silicone rubber molds are good for fragile samples because samples are easy to release; however, rubber molds provide poor dimension control.

\subsection{Characterizati on and tests}

Samples were released from Teflon ${ }^{\circledR}$ fluoropolymer molds after 1 day of curing and subsequently dried at room temperature. All samples were tested after at least 3 days of drying time. 2.3a Mechanical properties: Three hundred and four samples were tested to find optimal mixture and curing conditions of both CBPC and CBPC/GNPs. Using the optimized process 19 samples of CBPC and CBPC/GNPs were made measuring $6 \times 10 \times 100 \mathrm{~mm}^{3}$ for four point bending tests (3PBT) performed on an Instron 4411 machine, at a crosshead speed of $2.5 \mathrm{~mm} / \mathrm{min}$.

These 19 samples were tested 4 days after manufacturing. Additionally liquid/wollastonite ratios of 1.0 and $1 \cdot 1$ were tested. No difference was noted compared to the 1.2 ratio, except that the latter shows a neutral $\mathrm{pH}$.

2.3b Scanning electron microscopy (SEM): Sample sections were ground using silicon carbide papers of 500 , 1000, 2400 and 4000 grit. Once polished, the samples were first mounted on an aluminum stub and then sputtered in a Hummer 6.2 system at conditions of $15 \mathrm{~mA}$ A.C. for $30 \mathrm{~s}$ to obtain a thin film of $\mathrm{Au}$ of around $1 \mathrm{~nm}$. The SEM used was a JEOL JSM 6700R in a high vacuum mode.

2.3c X-Ray diffraction (XRD): The equipment used was a X'Pert PRO at $45 \mathrm{kV}$ scanning between $10^{\circ}$ and $80^{\circ}$. The samples were ground in an alumina mortar and $\mathrm{XRD}$ tests were done at room temperature.

2.3d X-Ray micro-tomography: The equipment used was a Desktop Micro CT-System (Skyscan 1072), run at the high resolution mode. The X-Ray source was powered at $70 \mathrm{kV}$ with a current of $141 \mu \mathrm{A}$; no filter was used. For each sample projections between $0.1^{\circ}$ and $180^{\circ}$ were taken in $0.25^{\circ}$ steps. The reconstruction was 
Table 3. Samples used in weight loss experiments.

\begin{tabular}{|c|c|c|c|c|c|c|c|c|c|c|c|c|c|c|c|c|}
\hline \multirow{2}{*}{$\frac{\text { Sample }}{\text { Sample identification }}$} & \multicolumn{6}{|c|}{$\begin{array}{l}\mathrm{CBPC} \text { processed at } \\
\text { air pressure }\end{array}$} & \multicolumn{6}{|c|}{$\begin{array}{c}\text { CBPC processed } \\
\text { with vacuum technique }\end{array}$} & \multicolumn{2}{|c|}{$\begin{array}{l}\text { CBPC/GNPs with } \\
\text { mixing time of } \\
\text { GNPs-acid of } 30 \mathrm{~s}\end{array}$} & \multicolumn{2}{|c|}{$\begin{array}{l}\text { CBPC/GNPs with } \\
\text { mixing time of } \\
\text { GNPs-acid of } 1 \mathrm{~h}\end{array}$} \\
\hline & n 0 & 1 & 2 & 3 & B1 & B2 & V0 & V1 & V2 & V3 & A1 & $\mathrm{A} 2$ & Cw1 & Cw2 & $\mathrm{C} 1$ & $\mathrm{C} 2$ \\
\hline Height (cm) & $5 \cdot 5$ & $3 \cdot 5$ & $2 \cdot 2$ & 0.5 & $7 \cdot 7$ & $1 \cdot 6$ & $5 \cdot 5$ & $3 \cdot 5$ & $2 \cdot 2$ & 0.5 & $7 \cdot 7$ & $1 \cdot 6$ & $7 \cdot 7$ & $1 \cdot 6$ & 7.7 & $1 \cdot 6$ \\
\hline Diameter (cm) & $19 \cdot 2$ & $19 \cdot 2$ & $19 \cdot 2$ & $19 \cdot 2$ & $35 \cdot 3$ & $35 \cdot 3$ & $19 \cdot 2$ & $19 \cdot 2$ & $19 \cdot 2$ & $19 \cdot 2$ & $35 \cdot 3$ & $35 \cdot 3$ & $35 \cdot 3$ & $35 \cdot 3$ & $35 \cdot 3$ & $35 \cdot 3$ \\
\hline
\end{tabular}
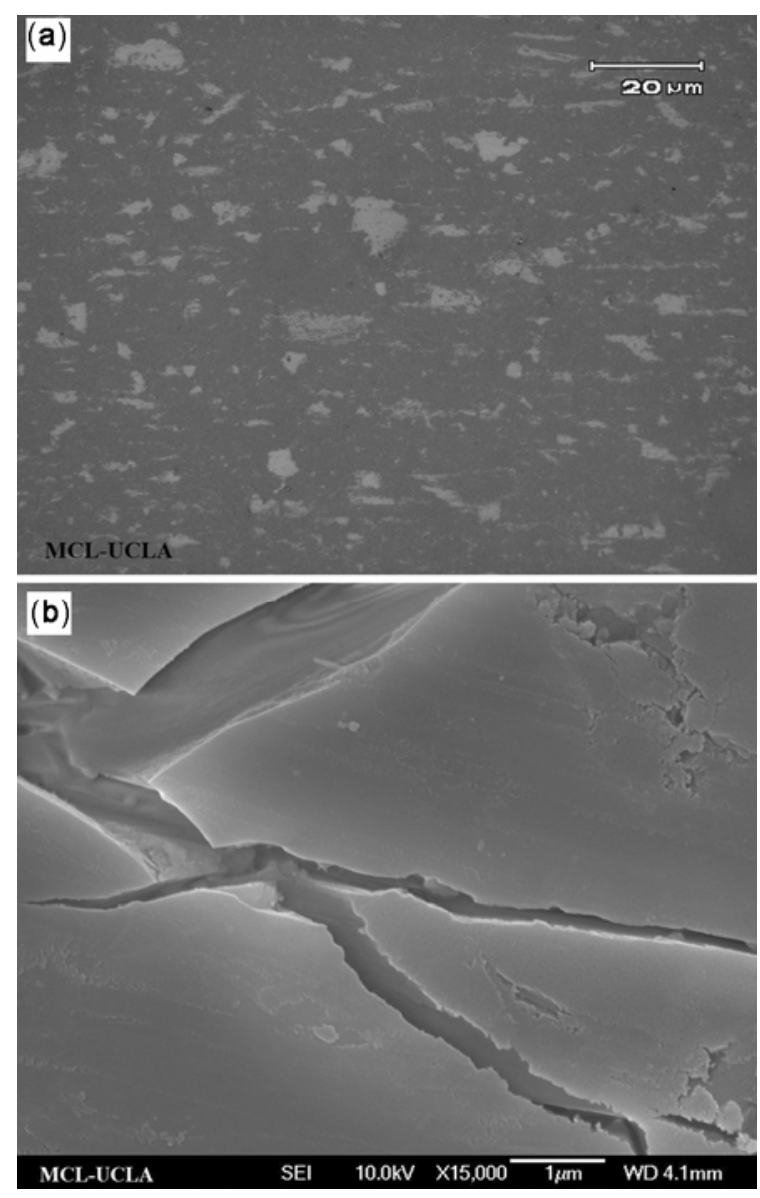

Figure 2. (a) OM of CBPC cross-section view, (b) SEM images of CBPC sample showing micro crack net.

obtained from 759 individual X-ray radioscopes of the cross-sections using the Skyscan-NRecon Software. 3D analysis was made by using external analysis program (CTAn) in the monochromatic mode.

2.3e pH tests: $\mathrm{pH}$ tests were determined with Whatman $\mathrm{pH}$ indicator paper $0-14$. Solid samples were ground and then diluted in $160 \mathrm{mg}$ of deionized water.

2.3f Weight loss: Sixteen samples (CBPC and CBPC/GNPs) were tested for around 100 days at room temperature to find the weight loss as a function of time. Samples were made in glass containers without caps.

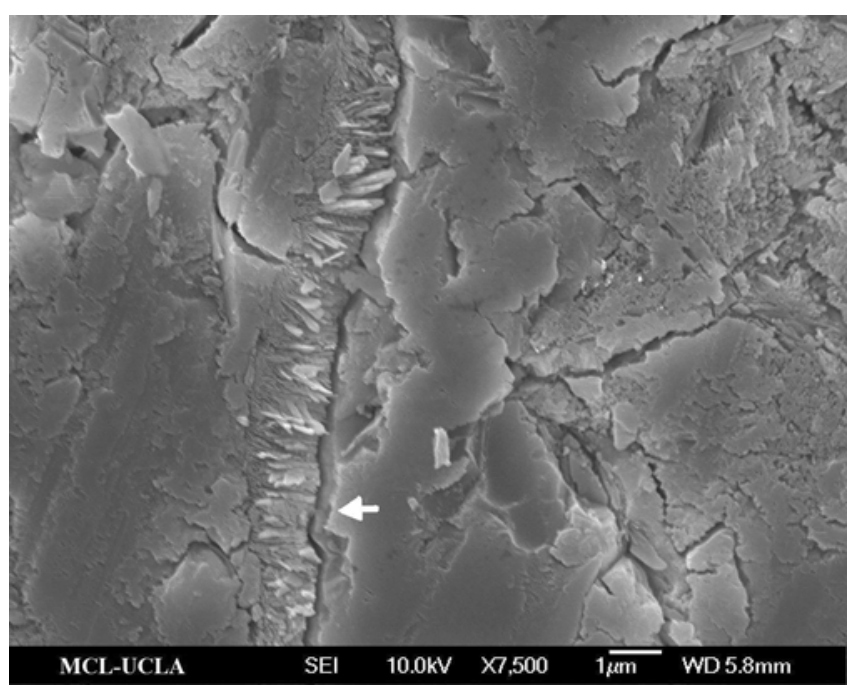

Figure 3. SEM image of CBPC of brushite crystals growing on Wo particle.

Samples were of six different thicknesses and two different cross-sectional areas. In addition, the effect of vacuum process on weight loss was registered by making samples for both vacuum and no vacuum technique during the manufacturing. For CBPC/GNPs, 2 different mixing times of GNPs-acid (30 s and $1 \mathrm{~h}$ ) were tested for two different thicknesses. These results are summarized in table 3 .

\section{Results}

The acid extracts the calcium from wollastonite powder once the mixing begins, a process described in (1) and (2), to produce the new phases of brushite, silica and calcium phosphates (Mosselmans et al 2007). The optimization and distribution of phases are major issues we are currently studying by X-ray tomography; the detailed analysis will be described in a separate communication.

The $\mathrm{pH}$ tests were performed after two days of manufacturing for CBPC and CBPC with $1 \mathrm{wt} \%$ of GNPs, and the $\mathrm{pH}$ was around 7 , which is neutral.

Optical microscopy (OM), scanning electron microscopy (SEM), X-ray diffraction (XRD) and weight loss techniques were used to analyse and characterize the specimens. OM of CBPC is shown in figure $2 a$, wherein some 
remaining wollastonite can be seen as white parts. No cracks or voids are visible at $7500 \times$. SEM of nanocracks in CBPC samples are shown in figure $2 b$. These cracks create a nano and micro void net, which is ideal for thermal insulation.

Figure 3 shows brushite crystals growing around a grain, corresponding to a primitive wollastonite particle. These macro and nano-cracks are generated because of material shrinking during the curing and loss of water molecules. Although these cracks are only visible by SEM, they are responsible for decreasing mechanical properties. However, the number of cracks can be controlled by varying process parameters like curing time and vacuum processing, so that the materials can be manufactured for both thermal and structural applications.

Nucleation of brushite on a wollastonite grain is shown in figures $4 a$ and $b$. The growth direction and shape of the microstructure are affected by the nucleation of amorphous silica and calcium phosphate in the matrix.

The distribution of crystalline phases (wollastonite and brushite) in the CBPC composite is shown in a
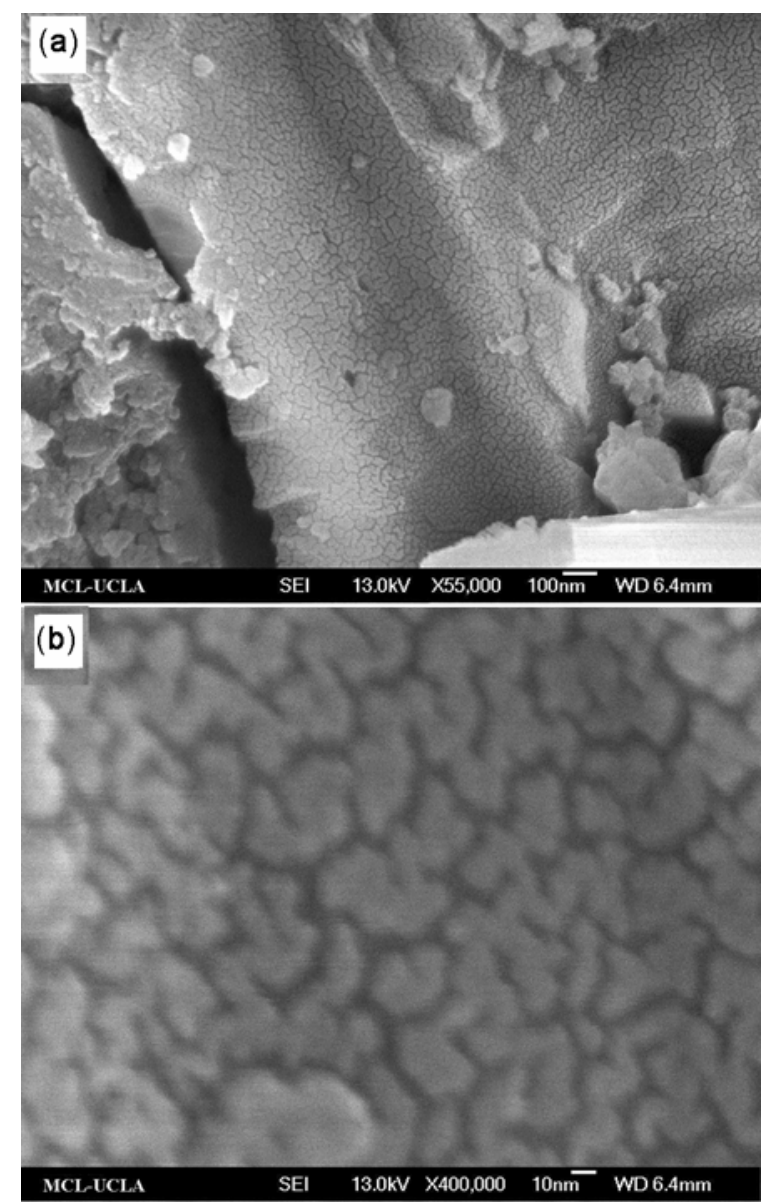

Figure 4. SEM images (a) primitive wollastonite crystal after $10 \mathrm{~s}$ etching time showing nucleation of brushite, (b) same image at higher magnification showing small brushite nuclei growing on a wollastonite crystal.
3-Dimensional X-ray microtomography image (figure 5b). Homogeneous distribution of crystalline phases can be seen from 3-dimensional X-ray microtomography image, figure 5. The amorphous phases do not appear in the 3 -D image, as shown in figure $2 \mathrm{a}$, because the technique is based on the emission of X-rays. The totally amorphous phases absorb the radiation and appear as black in the scanned images. In this case, amorphous phases appear as black in the monochromatic mode of the 3D- Skyscan software.

X-ray diffraction was performed on the cement samples to determine the phases present in the specimen. The indexed X-ray spectrum shown in figure 6 reveals that a fraction of wollastonite phase remains unreacted. The $\mathrm{CBPC}$ is a composite of different materials as shown in

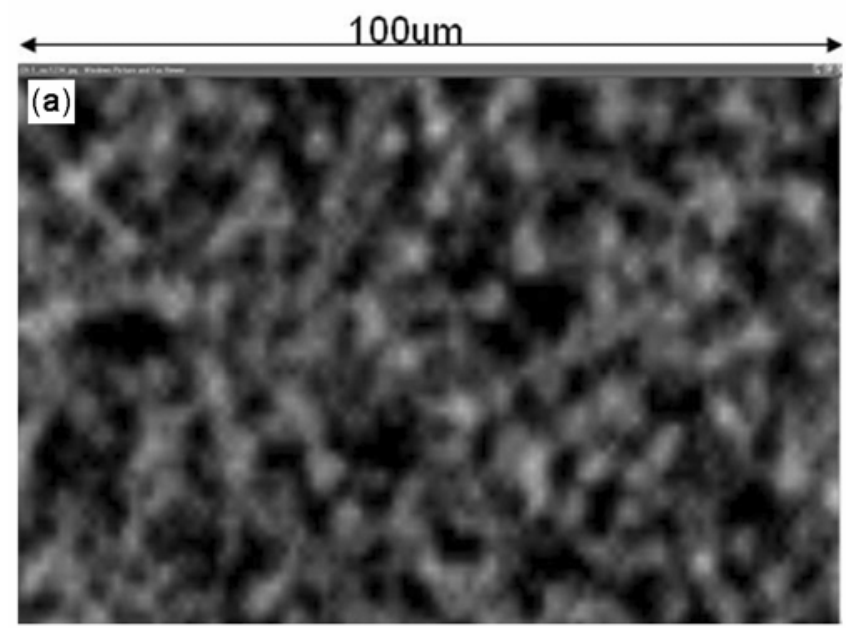

(b)

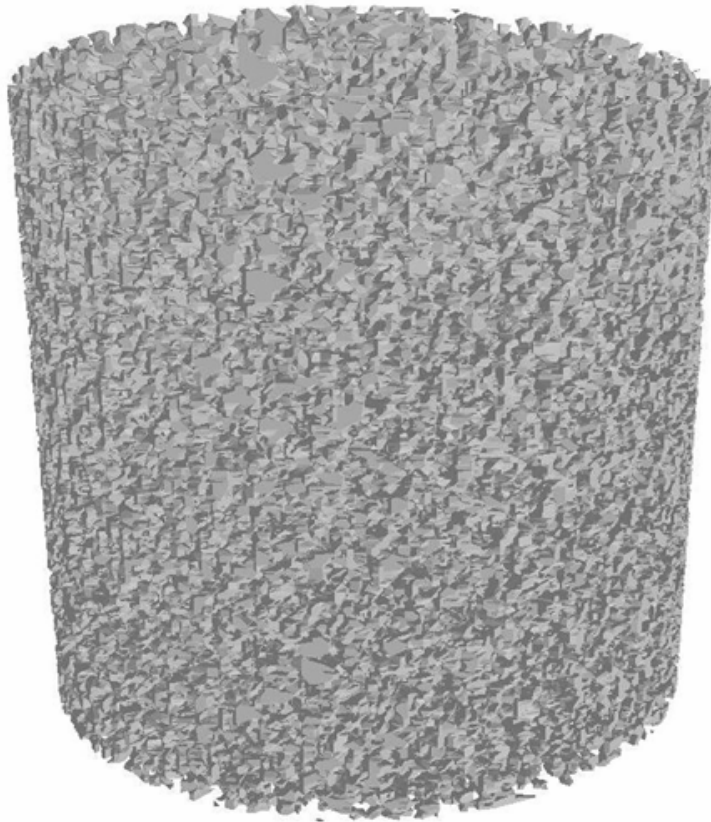

Figure 5. X-ray micro-tomography images, (a) 2-D image after reconstruction showing distribution of crystals on the matrix, (b) 3D image showing the distribution of crystals in the CBPC composite (cylinder of $1 \mathrm{~mm}$ height $\times 1 \mathrm{~mm}$ diameter). 
XRD: wollastonite, brushite, and calcium phosphate (Hanawalt et al 1938; Bale et al 1945; Murray and Dietrich 1956; Kern and Eysel 1993). In addition, amorphous calcium phosphate (Prokop et al 1998) and silica (Bertone et al 2003) are present in the specimen (see figure 6, upper part) but more experiments are needed in order to differentiate the contributions.

Figure 7 shows the XRD for the bulk and skin of CBPC of the sample. The main difference is in the brushite peaks, which appear more intense in the skin. Samples with GNPs show a dramatic improvement in mechanical properties.

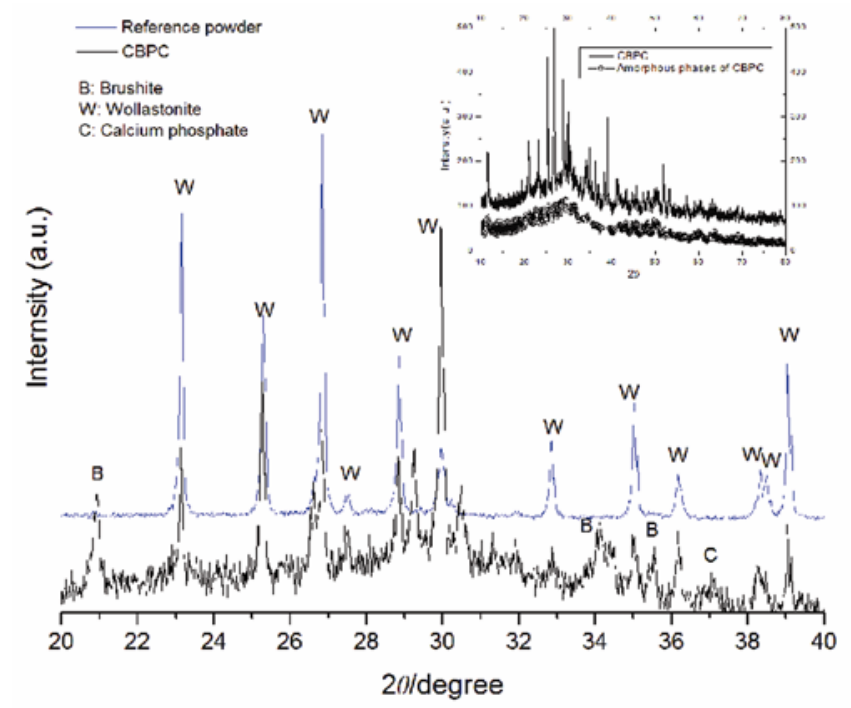

Figure 6. XRD spectra for reference wollastonite powder and CBPC. The amorphous phases are shown separated from crystalline phases (upper right).

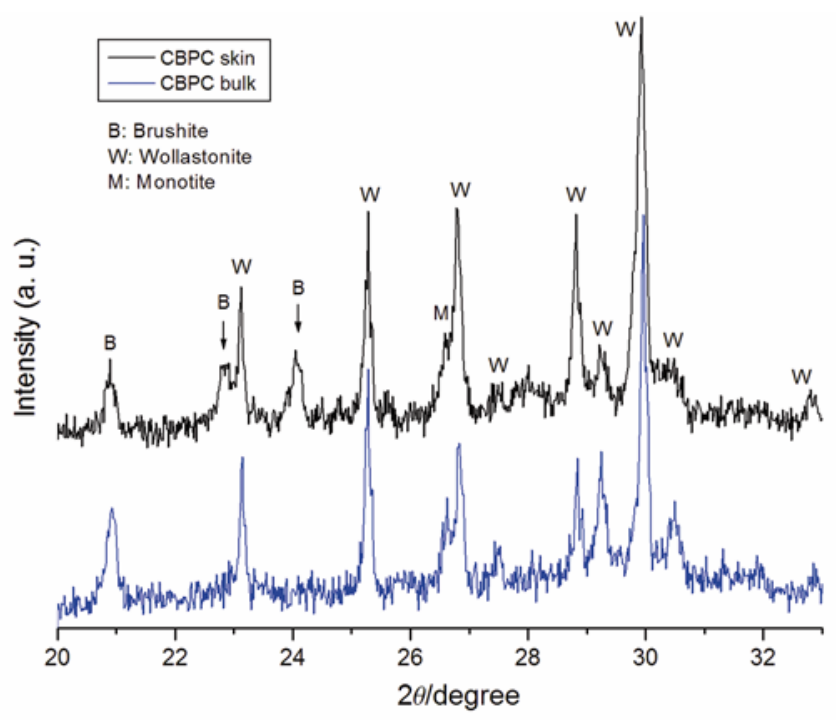

Figure 7. XRD for bulk and skin samples.
Figure 8 shows samples of CBPC reinforced with GNPs. Figure 8a, b shows the wollastonite crystals in the CBPC and the wollastonite grains, respectively after etching in acetic acid $1 \mathrm{wt} \%$ in water for $3 \mathrm{~s}$ and $10 \mathrm{~s}$, respectively. Clearly not all wollastonite grains are dissolved by the acid effect, even with increase in mixing time during manufacturing below room temperature.

Figure 9a illustrates that when using vacuum during the manufacturing of CBPC samples, weight loss (at room temperature) is around $10 \%$ with respect to non-vacuum processes. In addition, the \% weight loss increases by decreasing the thickness of the specimen. Stabilization time (for reaching plateau) increases for thicker samples. Figure 9b shows that GNPs reduced the weight loss by increasing the mixing time of GNPs-acid. Curing time is
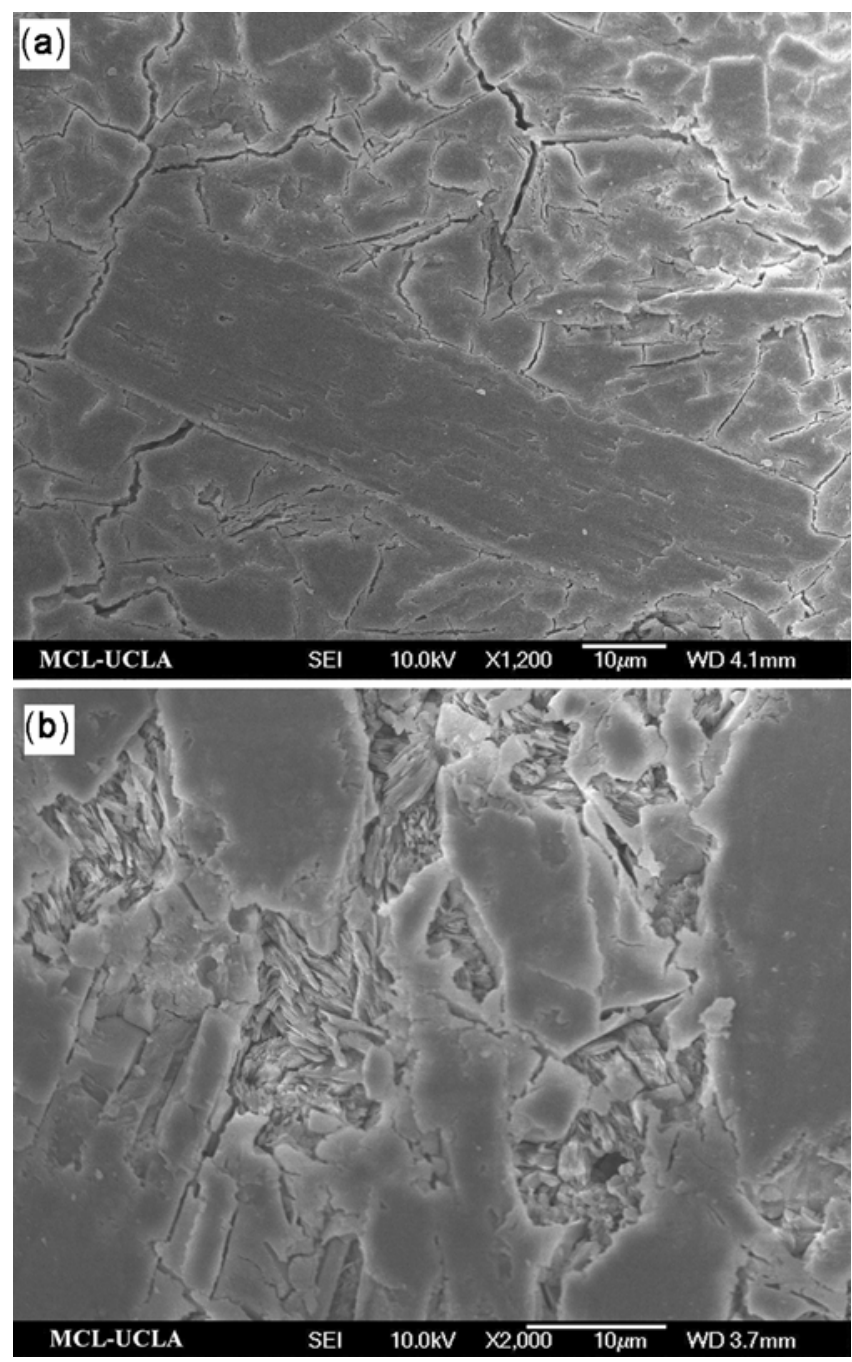

Figure 8. SEM images of CBPC reinforced with GNPs: (a) CBPC with primitive wollastonite crystals in the phosphate ceramic matrix after $3 \mathrm{~s}$ etching time (in acetic acid $1 \%$ in water); (b) brushite and primitive wollastonite crystals after 10 s etching time. 
also affected when vacuum process is used during manufacturing.

Figure 10a describes the stabilization time for weight loss (the time when weight loss becomes almost zero) with respect to increase in specimen thickness. For high weight loss (thin samples), stabilization time is short as described in figure $10 \mathrm{~b}$.

Finally, figure 11 shows $\mathrm{CBPC}$ and $\mathrm{CBPC}$ reinforced with GNPs with maximum stress improved more than $100 \%$. The summary of results is shown in table 4 . Additional research is being conducted to increase and measure the interfacial adhesion between GNPs and CBPC; this will be described in a separate communication.
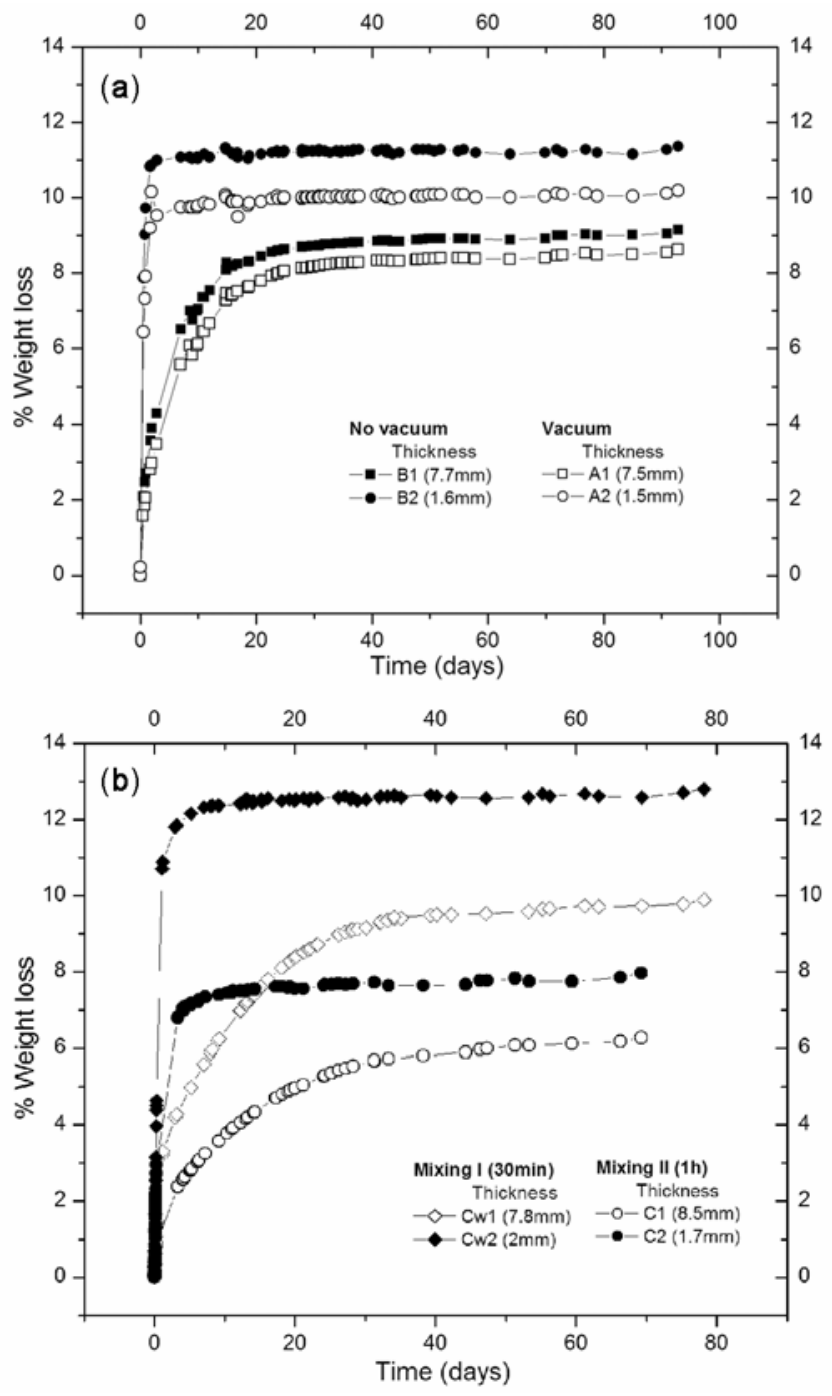

Figure 9. (a) Weight loss for $\mathrm{CBPC}$ with and without vacuum during the manufacturing for different thicknesses. (b) weight loss for $\mathrm{CBPC}+\mathrm{GNPs}$ samples for two mixing conditions $30 \mathrm{~min}, 1 \mathrm{~h}$ and thicknesses. Empty symbols indicate vacuum process used, filled symbols indicate vacuum process not used.

\section{Conclusions}

The main problem that CBPC presents in use in structural applications is the low values in bending strength. The presence during manufacturing of multi-scale voids, mainly from air, appears to reduce mechanical strength. Since the mixture is dense and curing is fast, obtaining good samples is a challenge. For these reasons we investigated different manufacturing procedures using vacuum technique. The resultant samples are free of voids. However, they are not free of micro and nano-cracks generated during the shrinkage process. Additional research is being conducted to reduce this problem.

In CBPC, the brushite phase has the lowest mechanical properties among all the phases, so one advantage of using GNPs is that they improve both brushite and
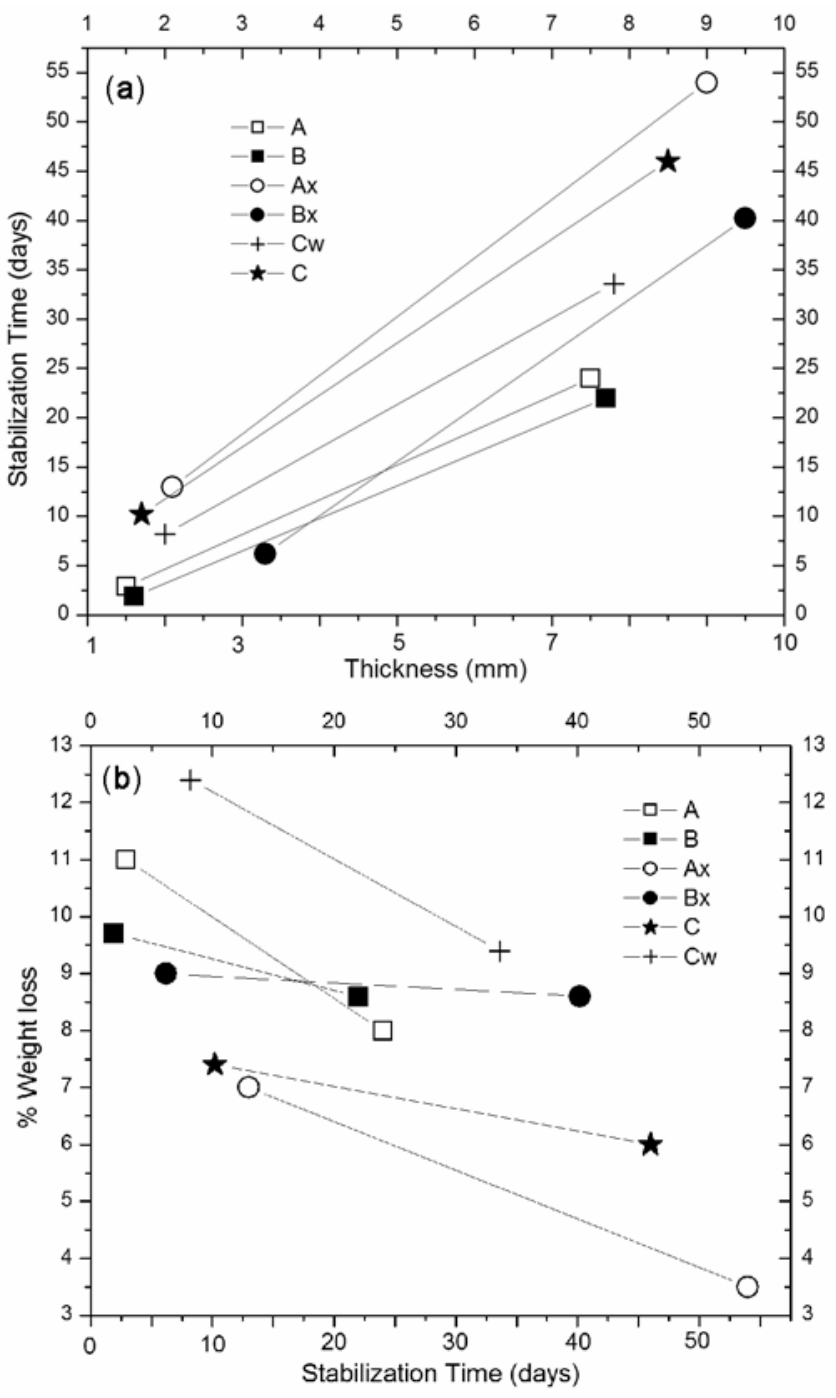

Figure 10. (a) Weight loss and stabilization time for different samples shown in figure 9, (b) stabilization time and thickness for different samples shown in figure 9 . 


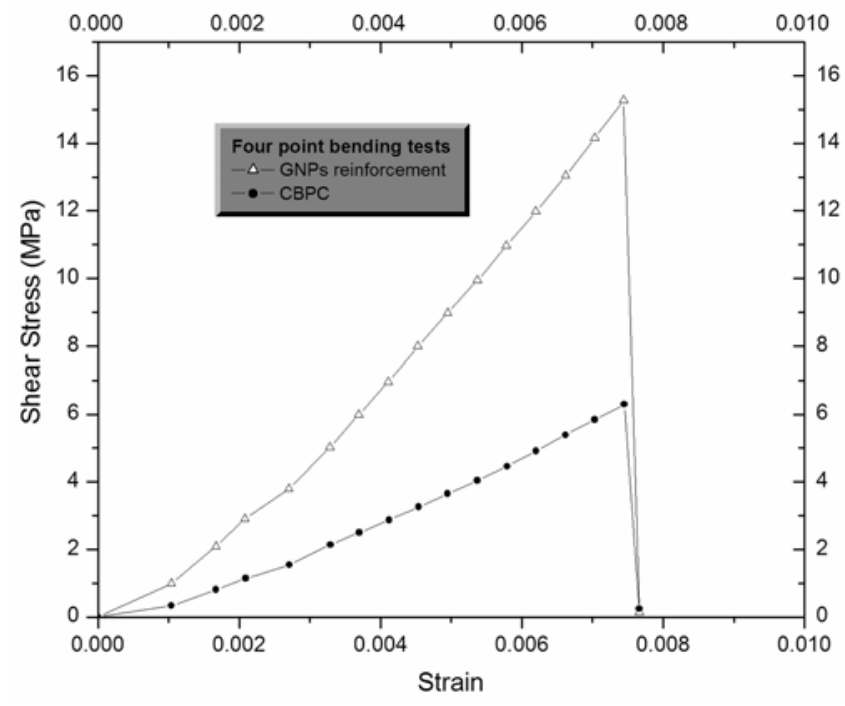

Figure 11. Four point bending tests for $\mathrm{CBPC}$ and $\mathrm{CBPC}$ with GNPs.

Table 4. Bending tests for CBPC.

\begin{tabular}{lcc}
\hline Sample & CBPC & GNPs reinforcement \\
\hline Max stress $(\mathrm{MPa})$ & $7 \pm 1$ & $14 \pm 1.4$ \\
\hline
\end{tabular}

amorphous calcium phosphates, enhancing the mechanical properties of the composite material.

Finally, two main results involving the mechanical properties of CBPC were obtained: a composite material with $1 \mathrm{wt} \%$ of added GNPs has a bending strength of $16 \mathrm{MPa}$, and after exposure to twenty months of ageing, it is expected to have a bending strength of at least $30 \mathrm{MPa}$. These achievements allowed the conclusion that CBPC could be a real solution for thermo-mechanical applications.

\section{Acknowledgements}

The authors wish thank the NIST-ATP Program through a grant to Composites and Solutions Inc. (Program
Monitor Dr. Felix H. Wu) and to COLCIENCIAS from Colombia for the grant to HAC.

\section{References}

Albee F H and Morrison H F 1920 Annu. Surg. 7132

Alshaaer Mazen $2006 \mathrm{Ph}$ D thesis (Vrije Universiteit)

Arun S 2004 Chemically bonded phosphate ceramics (USA: Elsevier Argonne National Laboratory)p. 283

Bale W F, Bonner J F, Hodge H C, Adler H, Wreath A R and Bell R 1945 Ind. Eng. Chem. (Anal. edn) 17491

Bertone Jane F et al 2003 Nano Letts 3655

Charrière E, Terrazzoni S, Pittet C, Mordasini Ph, Dutoit M, Lemaètre J and Zysset Ph 2001 Biomaterials 222937

Environmental Protection Agency AP 42 - Compilation of Air Pollutant Emission Factors, 2005 Volume I Stationary Point and Area Sources, Arunington, DC

Grover Liam M et al 2005 J. Mater. Chem. 154955

Grover Liam M, Hofmann Michael P, Gbureck Uwe, Kumarasami Balamurgan, Barralet Jake E. Frozen 2008 Acta Biomaterials doi:10.1016/j.actbio.2008.06.003

Hanawalt J D, Rinn H W and Frevel L K 1938 Anal. Chem. 10 475

Kern A and Eysel W 1993 Mineralogisch-Petrograph Inst. (Germany: University Heidelberg) ICDD Grant-in-Aid

LeGeros R, Chohayeb A and Shulman A 1982 J. Dent. Res. 61 343

Masahiko Kobayashi et al 1998 Bioactive bone cement: comparison of apatite and wollastonite containing glass-ceramic, hydroxyapatite, and b-tricalcium phosphate fillers on bonebonding strength. John Wiley \& Sons, Inc. CCC 00219304/98/020223-15

Mosselmans G, Monique Biesemans, Willem R, Wastiels J, Leermakers M, Rahier H, Brughmans S and Van Mele B 2007 J. Therm. Anal. \& Calorimetry 88723

Murray Jhon W and Dietrich R V 1956 Am. Mineral. 41616

Nihouannen Damien Le, Hacking S Adam, Uwe Gbureck, Komarova Svetlana V and Barralet Jake E 2008 Biomaterials 29 3253

NRMCA 2008 National Ready Mixed Concrete Association Concrete $\mathrm{CO}_{2}$ Fact Sheet. Publication Number $2 \mathrm{PCO}_{2}$

Prokop J et al 1998 Complexation in biological systems (Münster, Germany: Institute of Nuclear Physics)

Tamimi Faleh, Balamurugan Kumarasami, Charles Doillon, Uwe Gbureck, Damien Le Nihouannen, Enrique Lopez Cabarcos and Jake E Barralet 2008 Acta Biomaterialia 41315 